\title{
Muscarinic Acetylcholine Receptor M4
}

National Cancer Institute

\section{Source}

National Cancer Institute. Muscarinic Acetylcholine Receptor M4. NCI Thesaurus. Code C25921.

Muscarinic acetylcholine receptor M4 (479 aa, $~ 53 \mathrm{kDa}$ ) is encoded by the human CHRM4 gene. This protein is involved in acetylcholine-mediated signaling. 